\section{Media Resources: As An Effective Tool In Modern Education}

\author{
Umarova Zakhro
}
Doctoral Student, Tashkent State Pedagogical University Named After Nizami, Uzbekistan

\author{
G open aCcess \\ The American Journal of \\ Social Science And \\ Education Innovations \\ JULY 2020 \\ Page No.: 239-245 \\ Volume-II Issue-VII \\ PUBLISHED: 30 JULY 2020 \\ www.usajournalshub.com/inde \\ x.php/tajssei \\ Copyright: Original content \\ from this work may be used \\ under the terms of the \\ Creative Commons Attribution \\ 4.0 licence.
}

\title{
Abstract
}

The article substantiates the new role of media resources in modern education.

According to the author, the use of media resources in the educational process is a request of the modern conditions. Due to the media resources, quality education can be achievable.

Keywords: media resources, digitalization of education, visualization, learning with involvement, self-education.

\section{Introduction}

In our society, there is a growing need for skilled professionals who can quickly adapt to the changing conditions of the modern world. Today the main goal of any university is to have a highly-educated, independent thinker who can easily fulfill one's professional duties, adapt quickly to the rapidly developing technology and information flow, thinks critically and creatively, and integrates the opportunities and innovations into one's work.

Recent years, in universities and other educational institutions concentrated a large 
number of progressive and susceptible to new scientific and technical personnel. This greatly facilitates the introduction of new information technologies in educational institutions and makes it effective to develop new information systems for various state and commercial structures by the forces of these personnel. In this case, in the age of today's information society, it is not only enhancing computer literacy for future professionals, it also requires developing skills for handling information flow, developing their media and digital competencies. There is no doubt that, students who are able to quickly find the necessary information using technical means will be able to be more successful and timely determine the desired direction of development and personal growth.

In our country an educational system is currently being created to integrate into the world digital information - educational environment [3]. As our president says that, "in order to achieve sustainable development, we must deeply master digital knowledge and information technology, to enable us to take the shortest path to comprehensive progress. In today's world, digital technology plays a crucial role in all areas [1].

\section{The Main Findings And Results}

Digitalization of education system is one of the most important areas of digitalization of Uzbekistan and of course it affects to the digitalization of our economy. That is why in our country 2020 is called "The year of development of science-education and digital economy". The goal of digitalization of education is to radically increase the efficiency and quality of training to the level achieved in developed countries, i.e. training personnel with a new type of thinking that meets the requirements of the 21st century. One can achieve this goal only by improving the education system on the basis of the widespread introduction of new information and digital technologies, having solved the following tasks:

- Acquisition by future specialists of knowledge in the field of digital technologies and the skills of their application in their professional activities;

- Increasing the intensity and effectiveness of training, creating the conditions and means for self-education; 
- Increasing students' interest and motivation for learning;

- The restructuring of training methods, in particular the introduction of game, design, competitive and collective methods based on the use of digital tools and media resources.

We now live in a world with a rich flow of information. There is no doubt that it will be difficult for each person to assimilate the entire flow of information.

According to experts, there is a high dependence of the efficiency of assimilation and memorization of educational information on the form of its presentation and method of presentation. Numerous studies confirm the success of teaching with media resources: attention while working with a multimedia-based interactive training program, as a rule, doubles, and acquired knowledge is stored in memory much longer.

The use of multimedia in training programs, according to the results of a study by the Media Labs group of the Massachusetts Institute of Technology, increases "educability" by $3-4$ times, and the ability to memorize from average $30-35 \%$ to $75-85 \%$. This is achieved through combined exposure a variety of audio and video information, as well as through the use of interactive elements to engage the student in active actions in the learning process [2].

Using media resources allow to achieve in one training module a combination of information of various kinds - text, audio fragments, video, graphic drawings, infographics, animations, simulations, educational games etc. The use of media resources in the creation of training modular systems can significantly increase their visibility and, consequently, their effectiveness.

According to the research of the Salomon, students learn abstract, new, and novel concepts more easily when they are presented in both verbal and visual form. In Willingham's research he asks a simple question to make his point, "Why do students remember everything that's on television and forget what we lecture?" because visual media helps students retain concepts and ideas [5].

Media resources serve to enrich the educational process with visual materials and to increase the efficiency of student learning.

O. Soroka, I.Vasilyeva explained the benefits of visualization in learning: 
-Visualization helps students organize and analyze information correctly. Charts, diagrams, figures, memory cards contribute to the assimilation of large volumes of information, it is easy to remember and track the relationship between blocks of information;

- Visualization develops critical thinking;

-Visualization helps students integrate new knowledge;

- Visualization allows you to link the information received in a holistic picture of a particular phenomenon or object [4].

Using media engages students, aids student retention of knowledge, motivates interest in the subject matter, and illustrates the relevance of many concepts [6]. There is no doubt, a person better perceives exactly the information that is interesting to him, is most consistent with his personal preferences and attitudes, attractive for him. Therefore, the use of media resources in the learning process can be called the methodological concept of "learning with involvement".

In other words, if we train students with media resources, we can see the following results:

- Students will be involved in class and outside of class creative practical tasks;

- Students participate in interactive learning;

- Students collaborate;

-Students learn through research and search for new information and knowledge;

- It becomes easier to assimilate information to every student;

- Students will be responsible for their teaching.

Today there is not any person who does not face the media space, because media surround us. In the educational process, the role of media resources is important, as students have to constantly face an increasing amount of it. Media resources can improve the quality of training, especially self-education too.

There are some thoughts that, the special value of self-education is in independent search thinking, in the free assimilation of a freely chosen field of knowledge.

The learning process using media resources is adapted to the needs of a particular student and one's personal psychological characteristics. If introduce media resources in 
the educational process, it becomes possible for the student to choose the format of training and its pace, concentrate on a very narrow topic or, conversely, master an interdisciplinary program, in this way unified training programs are created and the student chooses his own individual learning path.

The methodology of using media resources in the educational process provides for classes based on problematic, heuristic, game based and other productive forms of learning that develop the individuality of the student, the independence of his thinking, stimulate his abilities in assimilation of knowledge through direct involvement in creative activity, perception, interpretation and analysis of media information.

In the modern educational system, the role of the media resource is changing: it is not only a means of transmitting information, but also a competing source of knowledge. Due to the media resources in educational process the mission of the teacher changes from the transfer of knowledge to mediation between students and various sources of knowledge, motivating students to search for and use certain knowledge, developing their competencies that allow them to use the information they receive for maximum selfrealization in various areas of life.

Some learners prefer acquiring knowledge through direct reading, some through listening comprehension, and still others through watching videos.

Edgar Dale, a well-known educator from the United States, studied the process of learning and remembering information. According to Dale, after two weeks we are able to recall only $10 \%$ of what we read, but $50 \%$ of what we saw and heard at the same time. (1-Figure) 


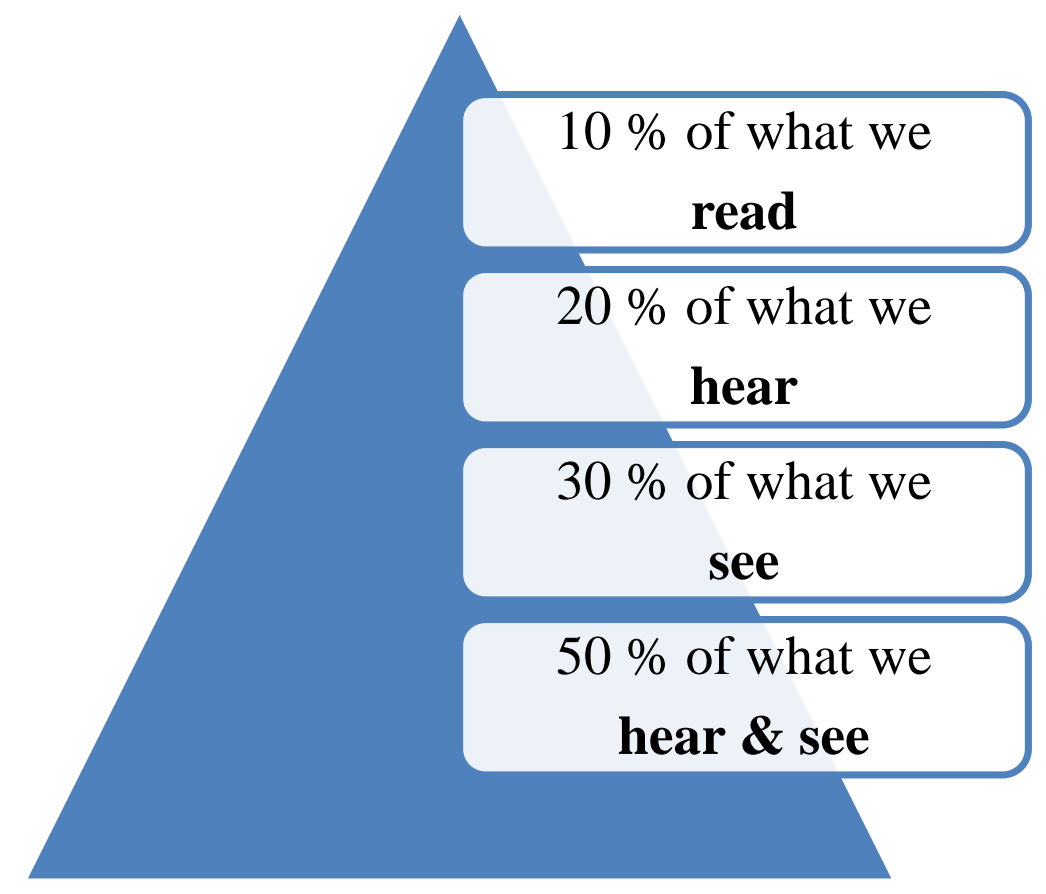

1 - Figure. Edgar Dale's cone of experience

It's worth figuring out what content is in principle interesting to a modern audience. This question was answered in detail by participants in an international study conducted by HubSpot analysts in 2016. The top watched content was video [7]. As mentioned above, the video is one of the effective format for the presentation of educational information that is most consistent with the psychology, physiology and self-interest of a person.

Perhaps that's why we often see training videos in MOOC contents.

But it's worth noting that video should not be the only source of training material. It would also be desirable if they would contain additional illustrations and a schematic image, animations, infographics etc. then the training material is perceived much better.

\section{Conclusion}

With this in mind, the organization of learning and independent learning of students with the help of media educational resources allows students to choose according to the level of perception and their interests.

All in all, media resources can be described as the main mean of the process of change in education. Result of that, education is becoming personality-oriented, where the 
main task is not to "force to learn", but to "help develop."

\section{References}

1. Text of President Shavkat Mirziyoyev's Address to the Oliy Majlis 24.01.2020

2. M. Maryev "Interactive multimedia courses as an element of the model of teaching informatics in rural schools of the Minusinsk region in the conditions of open education" Vestnik MGOU. Series "Pedagogy". - No. 2. Volume 2. - 2007. - M .: Publishing house of MGOU.

3. Z. Umarova "Fundamentals of the use of mobile technologies in teaching the subject" Web - programming and design "" Actual problems of computer science "Proceedings of the scientific-practical conference, -T.:2018.

4. O. Soroka, I. Vasilyeva "Visualization of educational information" University of pedagogical self-education №12 / 2015

5. Using media to enhance teaching and learning [https://serc.carleton.edu]

6. Why use media to enhance teaching and learning [https://serc.carleton.edu]

7. Such different readers: the whole truth about your users and not only / https://medium.com 